Rick Scott (Orcid ID: 0000-0002-0306-2376)

1

\title{
Income Tax and the Motivation to Work
}

\section{Corresponding Author: Scott Rick}

University of Michigan, Marketing Ross School of Business University of Michigan 701 Tappan Avenue Ann Arbor

Michigan United States 4810

Email Add:srick@umich.edu

http://orcid.org/0000-0002-0306-2376

\author{
Author: Gabriele Paolacci \\ Erasmus University, Rotterdam School of Management Rotterdam Netherlands \\ Email Add:gpaolacci@rsm.nl
}

\author{
Author: Katherine Burson \\ University of Michigan, Stephen M. Ross School of Business 701 Tappan St.E5612 Ann Arbor Michigan \\ United States \\ Email Add:kburson@umich.edu
}

This is the author manuscript accepted for publication and has undergone full peer review but has not been through the copyediting, typesetting, pagination and proofreading process, which may lead to differences between this version and the Version of Record. Please cite this article as doi: $10.1002 / \mathrm{bdm} .2078$

This article is protected by copyright. All rights reserved. 
Word Count: 9,314

This article is protected by copyright. All rights reserved. 


\title{
Income Tax and the Motivation to Work
}

\begin{abstract}
Does income tax influence the motivation to work? We propose that the degree of effort exertion in the presence of income tax depends on people's attitudes toward two key components of taxation: redistribution and government intervention. For people favorable toward both, working while taxed is aligned with personal identity and may actually enhance motivation. All others, however, may find taxes demotivating. In two incentive-compatible labor experiments, framing wages as subject to an income tax significantly increased productivity among people chronically favorable toward both redistribution and government intervention. For everyone else, taxes did not reliably influence productivity. An objectively equivalent intervention that did not redistribute a portion of participants' wages (framed as a wage "match" rather than a "tax") did not motivate anyone to work harder. Our findings suggest that the net effect of income tax on productivity partly depends on the distribution of attitudes toward redistribution and government intervention.
\end{abstract}

Keywords: income tax, motivation, identity, productivity, redistribution 
Does income tax influence the motivation to work? The nature of this potential relationship is difficult to predict. For example, Dan Ariely (2011) noted several possibilities: "some people think that [raising income taxes] will cause the wealthy to stop working, others think that this will cause everyone to stop working, yet others think that as long as we care about how we do relative to others an increase of the tax rate will have no effect on effort and productivity." A large body of research in macroeconomics has investigated this potential relationship, but has drawn somewhat conflicting conclusions (e.g., Keane, 2011; Saez, Slemrod, \& Giertz, 2012). Limited experimental research on the influence of income tax on effort has also documented opposing effects, with Kessler and Norton (2016) finding negative effects of income tax on effort, and Djanali and Sheehan-Connor (2012) and Fochmann et al. (2013) surprisingly finding positive effects.

Reconciling mixed findings may hinge on a better understanding of the individual-level psychological effects of income tax. Many share the intuition that, as taxes increase, taxpayers' motivation to work decreases (Srna, Zauberman, \& Schrift, 2015). In fact, some people have publicly considered an extreme reaction termed "going Galt" (quitting their jobs in response to what feels like unjust taxation), inspired by Atlas Shrugged hero John Galt (Etheridge, 2009). Indeed, some prior work on sales and carbon taxes suggests that many people find taxes distressing (Sussman \& Olivola, 2011; Hardisty, Johnson, \& Weber, 2010; see also McCaffery \& Baron, 2006). Income tax, in particular, has several properties that people find irritating. Although the U.S. federal income tax structure is progressive, many people feel that the rich do 
not pay their fair share due to loopholes and other policies that favor the rich (Pew Research, 2015). The tax code itself is complex and often misunderstood (e.g., Rees-Jones \& Taubinsky, 2016), producing frustration for many, particularly around the time that annual tax returns are due (Mulligan, 2010).

In addition to these factors, we propose that income tax has at its core two defining features that may or may not align with citizens' own attitudes and thus may lead to different effects on their motivation to work. First, income tax is typically viewed as redistributive (Helderman, 2012). In reality, some U.S. federal tax revenues finance programs that primarily help people with lower income (e.g., Medicaid), and other tax revenues finance programs that are not explicitly redistributive (e.g., National Defense). Nevertheless, the perception of income tax as primarily redistributive persists. For example, when considering the public's perception of income tax, Gordon Tullock (1971, p. 386), a founder of public choice theory, observed that the large amount of discussion around "the very minor phenomenon of redistribution from the wealthy to the poor" was "remarkable." Consistent with this over-emphasis on the redistributive effects of income tax, a conservative millionaire named Norman Litz took out a full-page ad in the New York Times in 2012 to argue, among other things, that "paying taxes is a form of charitable giving" (Rosenman, 2012).

We propose that the second defining feature of income tax is that it is a government intervention: It involves the government collecting a portion of taxpayers' income and making decisions about how this money should be spent. While some government expenditures are 
surely viewed as benign and necessary (e.g., fixing potholes), income tax is often viewed as a particularly "meddlesome" intervention (Lepore, 2012; Surowiecki, 2014). The lack of control over how one's tax dollars are spent is a key driver of many citizens' distaste for taxation (Lamberton, 2013).

It is worth emphasizing that, while redistribution can involve government intervention, the two activities are separable. It is entirely possible to have redistribution without government intervention (e.g., citizens choosing to donate some of their wealth to lower-wealth recipients) and government intervention without redistribution (e.g., collecting taxes to fund transportation infrastructure). ${ }^{1}$

Taxpayers likely vary in their feelings toward redistribution and government intervention. For example, while some people may be opposed to redistribution because they do not perceive much wealth inequality (Norton \& Ariely, 2011) or because they believe that redistribution undermines upward mobility (Benabou \& Ok, 2001), they might still believe that government intervention is generally positive. Conversely, some people may want to minimize government intervention, perhaps due to mistrust in government (e.g., Kuziemko et al., 2015) or philosophical objections, while engaging in redistributive efforts on their own terms (e.g., donating money). Others are likely to oppose both redistribution and government intervention, and still others are likely to favor both measures.

\footnotetext{
${ }^{1}$ When income tax is progressive, it could be argued that using tax revenues to fund public goods is a form of redistribution (e.g., Boadway \& Marchand, 1995). However, such expenditures are less prototypical examples of redistribution than expenditures that exclusively benefit lower-wealth citizens.
} 
These combinations of attitudes are unlikely to map perfectly onto political party affiliation. For example, Republicans differ in their support for redistributive policies (Matthews, 2014). Kuziemko et al. (2015, table 2) found that self-identified conservatives were split almost equally when asked whether they support increasing income tax rates for millionaires ( $45 \%$ favored an increase, 55\% did not). However, unlike political affiliation, the "Cultural Cognition Worldview" scale developed by Dan Kahan and colleagues (e.g., Kahan, 2012; Kahan, JenkinsSmith, \& Braman, 2011) essentially measures individuals' attitudes regarding the two central features of income tax. Despite its apparent relevance to income tax, the scale has previously been used to help explain people's reactions toward other policy-relevant issues, such as climate change (Kahan et al., 2012), gun control, and nuclear power (Kahan et al., 2007). The scale assesses respondents' attitudes toward social equality and redistribution (their level of "egalitarianism") by asking them to rate their agreement with statements such as, "We need to dramatically reduce inequalities between the rich and poor, whites and people of color, and men and women." The scale assesses respondents' attitudes toward government intervention (their level of "communitarianism") by asking them to rate their agreement with statements such as, “The government should do more to advance society's goals, even if that means limiting the freedom and choices of individuals." These attitudes tend to be related (e.g., people who desire societal equality also tend to believe government should play a strong role in citizens' lives), but they are far from perfectly correlated. In fact, Kahan (2012) noted that it is most appropriate to consider "four ways of life": people who are high on both egalitarianism and communitarianism 
(which we will refer to as "High E / High C" types), high on egalitarianism and low on communitarianism ("High E / Low C"), low on egalitarianism and high on communitarianism (“Low E / High C”), and low on both egalitarianism and communitarianism (“Low E / Low C”). ${ }^{2}$ Kahan et al. (2007, p. 471) argued that these attitudes represent "highly salient commitments that are likely to shape individuals' identities." Attitudes are important components of identity (Hogg \& Smith, 2007), and Oyserman (2009, p. 253) likens the stability of identities to the stability of attitudes. The potential identity-relevance of one's attitudes toward social equality and government intervention may have implications for motivation. Prior work in psychology suggests that individuals possess multiple identities (e.g., "rugged individual" or "Midwesterner," Oyserman 2009, p. 251), and identities that are made salient in a particular situation can influence cognition, motivation, and behavior (LeBoeuf, Shafir, \& Bayuk, 2010; Reed et al., 2012). In particular, identity-based theories of motivation posit that the extent to which aspects of a task align with salient identities influences motivation (e.g., Oyserman, 2007, 2009). This framework suggests that people experience a "motivational pull toward identity-

\footnotetext{
${ }^{2}$ Similar to Kahan's perspective, others have also conceptualized political preferences as more nuanced than simply left/right or liberal/conservative. Graham, Haidt, and Nosek (2009) developed a scale to measure five "moral foundations" that underlie political preferences: harm-avoidance (e.g., "It can never be right to kill a human being"), fairness (e.g., "Justice, fairness, and equality are the most important requirements for a society"), loyalty to the ingroup (e.g., "Loyalty to one's group is more important than one's individual concerns"), respect for authority (e.g., "If I were a soldier and disagreed with my commanding officer's orders, I would obey anyway because that is my duty"), and purity (e.g., "People should not do things that are revolting to others, even if no one is harmed"). In an Amazon Mechanical Turk survey measuring egalitarianism, communitarianism, and these five moral foundations (N $=305$ ), we found moderate relationships between egalitarianism and some of the foundations (e.g., egalitarianism scores correlated positively with fairness concerns, $r(303)=.36, p<.001)$. The relationships between the foundations and communitarianism were generally weaker (see Appendix A for the full set of correlations).
} 
congruent action" (Oyserman, 2009, p. 252) and are repelled by activities that conflict with salient identities.

From this perspective, the prospect of working in the presence of a salient income tax may be motivating to anyone high in egalitarianism (High E / High C types and High E / Low C types). In other words, egalitarians, who strongly desire greater societal equality, may find working in the presence of a salient income tax to be an identity-congruent, and thus motivating, experience. Alternatively, income tax may only be motivating to High E / High C types, who are favorable toward both central components of income tax. All others, who are unfavorable to at least one central component of income tax (redistribution and/or government intervention), may find working in the presence of a salient income tax to be identity-incongruent and, as a result, demotivating. Such a pattern would support our argument that income tax is spontaneously viewed as possessing two key features: it is redistributive, and it is a government intervention.

The notion that high levels of both egalitarianism and communitarianism may be needed to sustain motivation when income is taxed is broadly consistent with research aimed at understanding the predictors of tax avoidance (legally reducing one's tax liability by seeking loopholes, deductions or perhaps by reducing one's productivity at work) and tax evasion (illegally reducing one's tax liability by under-reporting one's taxable income). Several predictors of evasion have been identified (see Torgler, 2002 for a review), but one of the most prominent predictors is the perception that government is (in)competent (e.g., Alm \& Torgler, 2011; Gangl et al., 2013; Kirchler, Hoelzl, \& Whal, 2008; van Dijke \& Verboon, 2009). While 
Kahan's measure of communitarianism does not directly tap into perceptions of government competence, it is likely that people who favor strong government interventions also tend to view government as competent. Perceptions of the fairness of tax systems (e.g., the extent to which one's tax burden is viewed as similar to the tax burden of comparable others; Kirchler et al., 2008, 2014) also predict tax evasion. Kahan's measure of egalitarianism does not directly tap into perceptions of the fairness of tax systems, but people who want to "dramatically reduce inequalities between the rich and poor" are likely to view (progressive) tax systems as fair. Thus, prior work on tax evasion and compliance further bolsters our expectation that egalitarianism and communitarianism are likely to influence the motivation to work when income is taxed.

Notably, our account for the consequences of income tax is not incompatible with any of the previously discussed findings (e.g., Djanali \& Sheehan-Connor, 2012; Fochmann et al., 2013; Kessler \& Norton, 2016). Our framework suggests that the net effect of income tax on the motivation to work will depend partly on the prevalence of different attitudes toward redistribution and government intervention in the taxed population. Aside from important differences in methods across past experiments, our reasoning suggests that differences in the distributions of these relevant attitudes across study populations may have played a role in producing the divergent results.

In what follows, we use incentive-compatible, real-effort laboratory experiments to examine the relationship between income tax, egalitarianism, communitarianism, and the motivation to work. We manipulate whether or not income earned in the lab is subject to a tax, 
but we hold net wages constant across conditions. Thus, any influence of income tax on the motivation to work in our experiments cannot be explained by substitution effects (tax making leisure relatively more tempting) or income effects (tax producing a greater need to work to reach a desired earnings level). Instead, variation in the motivation to work can only be attributed to variation in psychological reactions to income tax, which we anticipate will be a function of the extent to which the task is experienced as identity-congruent. We do not exclude any participants or experimental conditions from our analyses, and we report all measures collected.

\section{Experiment 1}

In Experiment 1, we investigated how attitudes toward redistribution and government intervention moderate the influence of income tax on the motivation to work. Income tax in our experiment was redistributive: We told some participants (truthfully) that their tax payments would be redistributed to other students (participating in different studies). We did this to create a perception that is common outside the laboratory - namely, that income tax revenues benefit other people (Helderman, 2012; Rosenman, 2012). The beneficiaries of tax revenue in our experiment were not impoverished, but we did specify that these participants were working without the opportunity to earn their own study compensation. We reasoned that High E / High C types would find working in the presence of income tax to be identity-congruent. As a result, we predicted that they would be more motivated to work when their wages were taxed than when their wages were not taxed. By contrast, all other participants are likely to find working in the 
presence of income tax to be identity-incongruent. As a result, we predicted that they would be less motivated to work when their wages were taxed.

\section{Method}

Undergraduates at a large, public Midwestern university $(\mathrm{N}=233,50 \%$ female, age range: 19-25, mean age: 20.3) participated as part of a course requirement for “Mkt 300” (an introductory marketing class). We told participants that they would have the opportunity to earn money by performing a counting task. In each round of the task, adapted from Abeler et al. (2011), participants had to count the number of zeros contained within a $10 \times 15$ matrix of zeros and ones. The task was quite tedious (see Appendix B for sample). Participants earned $\$ 0.20$ for each acceptable response (within \pm 1 of the correct number). Participants earned nothing for unacceptable responses. Participants could complete up to 20 rounds (the maximum number of possible rounds was not revealed in advance). Participants could also choose to stop at any time. Specifically, at the beginning of each round, before displaying the next matrix, we asked participants "Do you want to count zeros in [a/another] matrix?" Participants clicked Yes or No; if they clicked Yes, we displayed the next matrix, and if they clicked No, the task concluded (and then participants completed survey measures, described below). We implemented this feature (explicit continue-or-stop decisions) to disentangle disinterest in beginning or continuing the task from simple counting mistakes. Without an opportunity to opt out of the task, a disinterested participant may simply make a series of guesses, which would ultimately be coded as a set of 
highly inaccurate responses. This experiment was conducted along with several other (unrelated) experiments (as part of a required session for students), so opting out of the task early meant moving on to the survey measures (described below) more quickly, as well as the next experiments, and thus being able to leave the lab session a few minutes early.

Participants were randomly assigned to one of two conditions. In the Control condition, participants were simply paid $\$ 0.20$ for each acceptable response. In the Tax condition, participants were initially paid $\$ 0.40$ per acceptable response, but $\$ 0.20$ in tax was immediately deducted. We (truthfully) told participants in the Tax condition (in the initial instructions) that "Your earnings will be subjected to a 50\% tax. The money raised through this tax will go to nonMkt300 students who participate in different studies with different tasks that do not allow participants to earn money themselves. To reiterate, you will obtain half of your earnings for completing the task, because 50\% will go towards the tax." Importantly, note that our tax manipulation did not influence the net pay participants received for each acceptable response: In both conditions, participants personally earned $\$ 0.20$ for each acceptable response. Thus, from a perfectly self-interested perspective, our manipulation should not influence participants' motivation to work. At the conclusion of each round, we informed participants whether their response was acceptable by displaying a paycheck (see Appendix B for samples).

At the conclusion of the task, participants completed the short-form of the Cultural Cognition Worldview scale (Kahan, Jenkins-Smith, \& Braman, 2011). The scale taps into the two central attitudes relevant to income tax (see Appendix B for the complete scale). The items 
were scored such that higher scores on the two subscales reflected greater egalitarianism and greater communitarianism, respectively. The mean inter-item correlation within each subscale (a measure of internal consistency that is independent of the number of items in the scale) was .35 and .19, respectively, both above the .15 threshold recommended by Clark and Watson (1995, p. 316). Neither egalitarianism scores nor communitarianism scores differed by condition (both $p$ s $>$.50). Egalitarianism and communitarianism scores were significantly correlated $(r(231)=.32$, $p<.001$; see Figure 1). Participants also indicated their political affiliation (Republican, Democrat, or Independent). We also administered some exploratory measures (listed in Appendix C), but we focus our analyses only on our central predictions.

\section{INSERT FIGURE 1 ABOUT HERE}

\section{Results and Discussion}

We utilized total earnings as our measure of participants' motivation to work. Total earnings are a function of the number of rounds attempted (i.e., the number of rounds where participants provided either an acceptable or unacceptable response) and precision (i.e., ability to approximately identify the correct number of zeros). Because there were generally few errors, total earnings correlated highly with the number of rounds attempted $(r(231)=.94, p<.001)$.

A regression of total earnings on a Tax condition dummy ( $=1$ for Tax condition, $=0$ for Control condition) revealed no main effect of our tax manipulation $(p=.43$; see Table 1 , Model 
1). To examine whether egalitarian and/or communitarian attitudes moderated the influence of our tax manipulation, we next regressed total earnings on Tax condition, egalitarianism scores, communitarianism scores (both mean-centered), and their interactions (Table 1, Model 2).

Because egalitarianism and communitarianism were correlated, we examined whether there was a potential multicollinearity problem in the multiple regression by assessing the variance inflation factors of each coefficient (VIFs; Hair et al., 2006). The highest VIF (2.26) was less than the standard cutoff of 5 (Hair et al. 2006), so we concluded that multicollinearity was not a significant concern here.

\section{INSERT TABLE 1 ABOUT HERE}

The regression revealed a significant Tax $\times$ egalitarianism interaction $(p=.004)$.

However, this two-way interaction was qualified by a significant Tax $\times$ egalitarianism $\times$ communitarianism interaction $(p=.006)$. We performed a spotlight analysis to probe this threeway interaction (Aiken \& West, 1991). Specifically, we examined the influence of tax on total earnings at high and low levels of both egalitarianism and communitarianism (1 SD above and below their respective means; see Figure 2). Tax marginally reduced earnings among Low E / Low C types $(p=.094)$, and significantly reduced earnings among Low E / High C types ( $p=$ .005). There was no effect among High E / Low C types $(p=.45)$. Critically, among High E / High C types, tax significantly increased total earnings $(p=.010)$.

This article is protected by copyright. All rights reserved. 


\section{INSERT FIGURE 2 ABOUT HERE}

Follow-up analyses confirmed that the only significant difference between High E / High C types and other participants was in the Tax condition. When we focused on the Control condition only, and regressed total earnings on egalitarianism scores, communitarianism scores (both mean-centered), and their interaction, we found a marginal effect of egalitarianism $(\mathrm{B}=$ $3.70, \mathrm{SE}=2.11, t(112)=1.76, p=.081)$, no effect of communitarianism $(p=.68)$, and, most importantly, no egalitarianism $\times$ communitarianism interaction $(p=.38)$. This indicates that High E / High C types were not especially motivated or demotivated in the Control condition. However, when we focused on the Tax condition only, and regressed total earnings on egalitarianism scores, communitarianism scores (both mean-centered), and their interaction, we found an effect of egalitarianism $(\mathrm{B}=5.39, \mathrm{SE}=2.24, t(113)=2.41, p=.018)$, no effect of communitarianism $(p=.20)$, and, most importantly, a significant egalitarianism $\times$ communitarianism interaction $(\mathrm{B}=1.19, \mathrm{SE}=.39, t(113)=3.02, p=.003)$.

We also investigated whether cultural worldview scores were simply a proxy for political affiliation. In other words, in this sample, was High E / High C just another label for Democrat (or non-Republican)? This is important to investigate given that political affiliation moderates reactions to some other taxes (Hardisty, Johnson, \& Weber, 2010; Sussman \& Olivola, 2011). Certainly, political affiliation is correlated with one's degree of egalitarianism and communitarianism. Both Democrats and Independents were significantly more egalitarian and 
communitarian than Republicans ( $p$ s $<.01$; Models 1 and 2 of Table 2). However, our subsequent analyses suggest that one's degree of egalitarianism and communitarianism more precisely captures reactions to income tax than political affiliation. Specifically, Models 3-5 of Table 2 reveal that political affiliation did not come close to moderating the influence of income tax on earnings.

\section{INSERT TABLE 2 ABOUT HERE}

Our analyses have treated total earnings as the sole dependent measure, but certainly other measures of the motivation to work could be constructed. For example, we could examine whether or not participants earned any money at all (21\% of participants earned nothing). To explore this alternate measure, we conducted a logistic regression predicting a binary Earn Anything (or not) variable, utilizing the same independent variables from Table 1, Model 2. As in the analysis of total earnings, we found a significant Tax $\times$ egalitarianism $\times$ communitarianism interaction $(p=.004)$. Spotlight analysis revealed that tax did not influence the probability of earning anything among Low E / Low C types $(p=.51)$ and High E / Low C types $(p=.11)$, and significantly reduced the probability of earning anything among Low E / High C types ( $p=$ .006). However, among High $\mathrm{E} /$ High $\mathrm{C}$ types, tax marginally increased the probability of earning anything $(p=.079)$. 
Thus, Experiment 1 provides initial evidence that the effect of income tax on the motivation to work depends on one's attitudes toward the central features of income tax (redistribution and government intervention). For those who are chronically opposed to either redistribution or government intervention, income tax has no consistent effect on motivation. For those who are chronically in favor of both redistribution and government intervention, working in the presence of income tax aligns with one's identity and is motivating.

Additionally, Experiment 1 rules out the most obvious potential alternative explanation for our findings, namely that egalitarian and communitarian attitudes just capture the effects of political affiliation. We assessed the plausibility of another alternative account in a follow-up survey on Amazon Mechanical Turk ( $\mathrm{N}=251,59 \%$ female, average age: 34$)$. We explored whether High E / High C types are simply people who reject the notion of a "just world" (i.e., a world where people get what they deserve and deserve what they get; Lerner, 1982). Benabou and Tirole (2006; cf. Frank, Wertenbroch, \& Maddux, 2015) proposed that people who reject the notion of a just world are most likely to favor redistribution via income tax, because hard work is presumably not sufficient to raise the less fortunate out of poverty. However, when we regressed belief in a just world scale scores (measured with the Rubin \& Peplau, 1975 scale; mean interitem correlation: .22) on mean-centered egalitarianism scores, mean-centered communitarianism scores, and their interaction, we found a significant relationship with egalitarianism $(\mathrm{B}=-.03, \mathrm{SE}$ $=.006, t(247)=4.70, p<.001)$, no relationship with communitarianism $(p=.14)$, and, most importantly, no interaction $(p=.90)$. 
Another possibile alternative account is that High E / High C types are essentially "social surplus maximizers," who are happy to generate as much money (for self and others) as possible when given the opportunity. That is, rather than experiencing the motivational benefits of identity-congruence while working in the presence of income tax, it is possible that High E / High $\mathrm{C}$ types were motivated by the opportunity to maximize the sum of money earned for themselves and for others. Theoretically, it is unclear why surplus-maximizers would happen to be strongly in favor of redistribution and government intervention, but based on Experiment 1 alone, we cannot rule out the possibility that High E / High C types were primarily motivated by the opportunity to maximize social surplus. Experiment 2 explores this possibility.

\section{Experiment 2}

To test the alternative hypothesis that High E / High C types are essentially social surplus-maximizers, we introduced a "Match" condition that allowed participants to generate money for themselves and others in the absence of taxation. In both the Match and Tax conditions, acceptable responses produce the same monetary outcomes for participants and other students. However, in the Match condition, the experimenter matches a portion of participants' gross earnings with the experimenter's money, and distributes the experimenter's money to other people. In other words, Match participants have the same opportunity (as Tax participants) to generate revenue for other participants, but none of it comes out of their gross earnings. Thus, the Match condition essentially removes both the intervention component (we do not collect 
money from participants) and the redistribution component (we do not redistribute collected funds to other participants). Our identity-congruence account predicts that the Match condition should not especially motivate High E / High C types. By contrast, the surplus-maximization account predicts that the Tax and Match conditions are equally likely to motivate High E / High C types.

In Experiment 2, we also examine the replicability of the basic Tax $\times$ egalitarianism $\times$ communitarianism interaction observed previously. We attempt to increase the generalizability of our findings by examining the effects of a different tax rate: $33 \%$ (rather than $50 \%$ in Experiment 1). Although both rates are high compared to average U.S. tax rates, they are comparable to average tax rates in some European countries (e.g., Denmark, Sweden). These tax rates are also comparable to rates utilized in prior experimental research (e.g., $50 \%$ in Kessler \& Norton, 2016; 20-80\% in Djanali \& Sheehan-Connor, 2012; 25\% and 50\% in Fochmann et al., 2013).

\section{Method}

Undergraduates at a large, public Midwestern university $(\mathrm{N}=358,45 \%$ female, age range: $18-26$, mean age: 19.9) participated as part of a course requirement for “Mkt 300" (an introductory marketing class). We told participants that they would have the opportunity to earn money by performing a counting task - the same task from Experiment 1. (None of the Experiment 2 participants had participated in Experiment 1.) All participants personally earned 
$\$ 0.20$ for each acceptable response (within \pm 1 of the correct number), and nothing for unacceptable responses. Participants could complete up to 20 rounds, and they could choose to stop at any time.

Participants were randomly assigned to one of three conditions. In the Control condition, participants were simply paid $\$ 0.20$ for each acceptable response. In the Tax condition, participants were initially paid $\$ 0.30$ per acceptable response, but $\$ 0.10$ in tax was immediately deducted. As in Experiment 1, we told participants in the Tax condition (in the initial instructions) that their taxes would be redistributed to other students. Specifically, in the Tax condition, we told participants:

\begin{abstract}
Your earnings in this study will be subjected to a 33\% tax. The money collected through this tax will go to non-Mkt300 students who participate in different studies with different tasks that do not allow participants to earn money themselves. To reiterate, you will obtain two thirds of your gross earnings for completing the task, because $33 \%$ will go towards the tax.
\end{abstract}

In the Match condition, participants personally earned $\$ 0.20$ for each acceptable response. In addition, for each acceptable response, the experimenter allocated $\$ 0.10$ to other students. Specifically, in the Match condition, we told participants:

A portion of your earnings in this study will be matched by a payment from us to other students. That is, every time you earn money, we will pay the equivalent of one half of your earnings to other students. These are non-Mkt300 students who participate in 
different studies with different tasks that do not allow participants to earn money themselves. To clarify, this procedure will not reduce your earnings in any way. Instead, we will use our budget to make these additional payments.

Thus, in every condition, participants personally earned $\$ 0.20$ for each acceptable response. Also, in both the Tax and Match conditions, each acceptable response also produced $\$ 0.10$ for other students. Critically, however, the Tax and Match conditions differ in how that $\$ 0.10$ for other students is framed (as a tax or as matched revenue coming from the experimenter). At the conclusion of rounds in which the participant provided an acceptable response, we displayed animations illustrating their payments (see Appendix B). If participants provided an unacceptable response, we simply informed them of that fact (without animation). ${ }^{3}$

At the conclusion of the task, participants completed the short-form of the Cultural Cognition Worldview scale. The mean inter-item correlation was .42 for the egalitarianism dimension, and .23 for the communitarianism dimension. Neither egalitarianism scores nor communitarianism scores differed by condition (all $p \mathrm{~s}>.15$ ). Egalitarianism and communitarianism scores were significantly correlated $(r(356)=.28, p<.001$; see Figure 3$)$. We also administered exploratory measures (listed in Appendix C), but we focus our analyses only on our central predictions.

\footnotetext{
${ }^{3}$ Although correct responses produced identical monetary outcomes in the Tax and Match conditions, the percentage of gross wages allocated to other students necessarily differed between the conditions (33\% in the Tax condition, 50\% in the Match condition). This was not ideal, but ultimately unavoidable (either the amount of money or gross wage percentage allocated to other students must differ between Tax and Match conditions). However, the animation participants viewed after each acceptable response (Appendix B) emphasized amounts rather than percentages (showing one dime allocated to other students in both the Tax and Match conditions).
} 


\section{INSERT FIGURE 3 ABOUT HERE}

\section{Results and Discussion}

A regression of total earnings on a Tax condition dummy $(=1$ for Tax condition, $=0$

otherwise) and a Match condition dummy (= 1 for Match condition, = 0 otherwise) revealed no main effects our manipulations ( $p$ s > .25; see Table 3, Model 1). We next regressed total earnings on Tax condition, Match condition, egalitarianism scores, communitarianism scores (both mean-centered), and their interactions (Table 3, Model 2). The VIFs for the eleven independent variables were all in an acceptable range (from 1.38 to 3.29). We found a significant Tax $\times$ communitarianism interaction $(p=.018)$. Critically, this two-way interaction was qualified by a significant Tax $\times$ egalitarianism $\times$ communitarianism interaction $(p=.036)$. There was no Match $\times$ egalitarianism $\times$ communitarianism interaction $(p=.69)$. We performed a spotlight analysis to probe both the Tax $\times$ egalitarianism $\times$ communitarianism interaction and the (nonsignificant) Match $\times$ egalitarianism $\times$ communitarianism interaction. Specifically, we examined the influence of the Tax and Match treatments on total earnings at high and low levels of both egalitarianism and communitarianism (1 SD above and below their respective means; Figure 4).

\section{INSERT TABLE 3 ABOUT HERE}

This article is protected by copyright. All rights reserved. 
Relative to the Control condition, tax marginally reduced total earnings among Low E / Low $\mathrm{C}$ types $(p=.087)$. There was no effect of tax among Low E / High C types $(p=.48)$ or High E / Low C types $(p=.12)$. However, among participants high in both egalitarianism and communitarianism, tax significantly increased total earnings relative to the Control condition $(p$ $=.009)$. By contrast, earnings in the Match condition did not significantly differ from earnings in the Control condition at any level of egalitarianism and communitarianism (all $p s>.25$ ). This suggests that High E / High C types are not simply motivated to maximize social surplus. Rather, they appear to experience the motivational benefits of identity-congruence while working in the presence of income tax.

\section{INSERT FIGURE 4 ABOUT HERE}

Follow-up analyses confirmed that the only significant difference between High E / High C types and other participants was in the Tax condition. When we focused on the Control condition only, and regressed total earnings on egalitarianism scores, communitarianism scores (both mean-centered), and their interaction, we found no significant interaction $(p=.35)$. Likewise, when we focused on the Match condition only, and regressed total earnings on egalitarianism scores, communitarianism scores (both mean-centered), and their interaction, we found no significant interaction $(p=.18)$. This indicates that High E / High C types were not especially motivated or demotivated in either the Control or Match conditions. However, when 
we focused on the Tax condition only, and regressed total earnings on egalitarianism scores, communitarianism scores (both mean-centered), and their interaction, we found a marginally significant interaction $(\mathrm{B}=.58, \mathrm{SE}=.31, t(115)=1.89, p=.061)$

\section{General Discussion}

Income tax is a salient presence in the lives of many employees. Whether or not employees routinely inspect the tax witholdings reported on their pay stub, the annual need to complete income tax returns and frequent political debates over income tax are likely to prompt employees to consider, from time to time, how income tax influences their take-home pay. Thus, it is important to consider how the presence of income tax influences individuals' motivation to work. Intuition suggests that income tax is unlikely to bolster motivation (Srna, Zauberman, \& Schrift, 2015). However, for some people, we found that the presence of income tax can actually enhance motivation and productivity. People whose identities are strongly tied to proredistribution and pro-government beliefs worked significantly harder when taxed than when not taxed, presumably because working while taxed was identity-congruent for them (Oyserman, 2009). We ruled out the possibility that these participants were simply social surplus maximizers by demonstrating that a wage "match" (objectively equivalent to our wage "tax") did not motivate them to work harder.

Most participants in our samples were not favorable toward both redistribution and government intervention (Figures 1 and 3). Among these participants, income tax did not 
consistently influence motivation and productivity. Thus, pooling across all participants, there was no main effect of the presence of income tax on productivity. Our results suggest that the net effect of income tax on productivity partly depends on the distribution of attitudes toward redistribution and government intervention in the relevant population. Our conceptual framework may help to explain why previous tax experiments that utilized different samples reached different conclusions about the net influence of income tax on motivation (e.g., Djanali \& Sheehan-Connor, 2012; Fochmann et al., 2013; Kessler \& Norton, 2016).

One concern with our interpretation of the results is that, because egalitarianism and communitarianism are significantly correlated $(r(231)=.32$ in Experiment $1 ; r(356)=.28$ in Experiment 2), the key Tax $\times$ egalitarianism $\times$ communitarianism interaction term may actually be capturing the interactive effect of Tax $\times$ egalitarianism $^{2}$ or Tax $\times$ communitarianism $^{2}$. We explored this possibility by running alternate versions of our key regression models (e.g., in experiment 1 , replacing the egalitarianism $\times$ communitarianism and Tax $\times$ egalitarianism $\times$ communitarianism terms with egalitarianism ${ }^{2}$ and Tax $\times$ egalitarianism $^{2}$ terms). All the alternate models yielded lower $\mathrm{R}^{2}$ values than the original models (.06 and .04 vs. .07 in Experiment $1 ; .03$ and .04 vs. .05 in Experiment 2). These results suggest that the key Tax $\times$ egalitarianism $\times$ communitarianism interaction term does not simply reflect the interactive effect of Tax and egalitarianism $^{2}$ or Tax and communitarianism ${ }^{2}$.

The results support our argument that income tax is spontaneously viewed as possessing two key features: it is redistributive, and it is a government intervention. However, the explicitly 
redistributive nature of our income tax may have inflated the relevance of the egalitarianism and communitarianism constructs. In other words, if the tax implemented in our experiments was not explicitly redistributive, we may have observed a weaker Tax $\times$ egalitarianism $\times$ communitarianism interaction. We cannot rule out this possibility based on our experiments. However, to partially address this concern, we utilized data that Dan Kahan generously shared with us. Kahan collected Cultural Cognition Worldview (short-form) scale responses and responses to other items over a six-year period (2007-2012) from a nationally representative sample. One dataset included a particularly relevant item. Specifically, in one sample $(\mathrm{N}=$ 1,484), Kahan asked respondents, on a 1 (strongly oppose) to 6 (strongly favor) scale, "How strongly do you oppose or support eliminating the estate tax?" The estate tax (also known as the "death tax") is highly progressive and redistributive, but unlike the tax in our experiments, the question did not emphasize that. We regressed the extent to which respondents favored eliminating the estate tax on mean-centered egalitarianism and communitarianism scores and their interaction. There was a significant main effect of egalitarianism $(\mathrm{B}=-.085, \mathrm{SE}=.011$, $t(1,480)=7.48, p<.001)$, a significant main effect of communitarianism $(\mathrm{B}=-.070, \mathrm{SE}=.014$, $t(1,480)=4.97, p<.001)$, and, most importantly, a significant egalitarianism $\times$ communitarianism interaction $(\mathrm{B}=-.008, \mathrm{SE}=.003, t(1,480)=2.27, p=.023)$. In line with our experimental results, spotlight analyses revealed that estimated favorability toward eliminating the estate tax among High E / High C respondents (4.07) was clearly lower than among Low E / Low C respondents (5.04), Low E / High C respondents (4.81), and High E / Low C respondents 
(4.60). Thus, the correlational results derived from Kahan's datasets help to mitigate the concern that the Tax $\times$ egalitarianism $\times$ communitarianism interaction observed in our experiments was an artifact of the way our income tax was framed.

Other limitations should be acknowledged. As in previous experimental research examining the effects of tax on productivity (e.g., Kessler \& Norton, 2016, left panel of Tables 1 and 2), the $\mathrm{R}^{2}$ values in our regressions predicting productivity were low. Clearly, unobserved factors (e.g., perhaps the extent to which one's egalitarianism and communitarianism are salient aspects of one's identity, one's tolerance for tedious tasks, one's conscientiousness, and/or one's need for money) also influenced productivity in our paradigm. Also, tax revenues in our paradigm were redistributed to other students at the participants' university, and not to unknown others (as taxpayers often feel is the case). Taxes may be less motivating to High E / High C types when tax revenues are redistributed to completely unknown recipients. Finally, note that our experiments necessarily focused on the initial effects of introducing an income tax on motivation, rather than the long-run effects of income tax. It is unclear whether the routine, repeated payment of income tax has different effects on the motivation to work (or maybe even one's level of egalitarianism and/or communitarianism).

Our work raises several questions worthy of future research. For example, we proposed that the two central features of income tax are redistribution and government intervention, but arguably the "tax" label itself could also be considered a central feature (cf. Durham, Manly, \& Ritsema, 2014; Eckel, Grossman, \& Johnston, 2005; Hardisty, Johnson, \& Weber, 2010). It 
would be interesting to examine whether different labels for taxes (e.g., "dues") produce effects on motivation similar to those observed here. Relatedly, one could compare a (no-tax) control condition to a " $0 \%$ tax" condition; it is possible that the explicit absence of income tax may actually be demotivating to High E / High C types. To assess generalizability, future research could investigate how egalitarianism and communitarianism influence reactions toward progressive taxes. Our results, which relied on experiments that implemented flat taxes (i.e., tax rates did not depend on how much participants had already earned), may understate the extent to which people who are not High E / High C types find progressive income tax to be irritating. It is also worth examining how variance in the salience of income tax influences the motivation to work among different types of employees (cf. Chetty, Looney, \& Kroft, 2009). Should income tax withholding be made even more salient (e.g., on pay stubs) in High E / High C populations? Could a high-stakes reminder of income tax (e.g., filing one's annual tax return) reduce motivation among employees who are not favorable toward both redistribution and government intervention? The answers to these questions may have implications for tax policy and consumer welfare.

Our work not only provides new reasons to consider the optimal framing and salience of income tax, but also raises questions about how egalitarian and communitarian attitudes develop in the first place. Given the necessity of taxing income, one implication of our work might be that society would be better off if it could find ways to enhance citizens' levels of egalitarianism and communitarianism. Of course, beyond the domain of motivation and productivity, there may 
be negative consequences of high levels of egalitarianism and communitarianism that we cannot observe here. Those broader implications, as well as the processes by which egalitarian and communitarian attitudes develop, are worthy of additional research.

\section{Acknowledgement}

We thank Dan Kahan for sharing data that we analyzed in our General Discussion and Ye Li for help in identifying the labor task we used in our experiments. This research was supported by a Mary K. Hallman Fellowship (to Burson) from the Ross School of Business.

\section{References}

Abeler, J., Falk, A., Goette, L., \& Huffman, D. (2011). Reference points and effort provision. American Economic Review, 101(2), 470-492.

Aiken, L.S., \& West, S.G. (1991). Multiple regression: Testing and interpreting interactions. Sage, Thousand Oaks, CA.

Alm, J., \& Torgler, B. (2011). Do ethics matter? Tax compliance and morality. Journal of Business Ethics, 101, 635-651.

Ariely, D. (2011). What are the effects of taxes on motivation and productivity? TED.com (February), http://www.ted.com/conversations/24/what_are_the_effects_of_taxes.html.

Aron, A., Aron, E. N., \& Smollan, D. (1992). Inclusion of other in the self scale and the structure of interpersonal closeness. Journal of Personality and Social Psychology, 63(4), 596-612.

Benabou, R., \& Ok, E. (2001). Social mobility and the demand for redistribution: The POUM hypothesis. Quarterly Journal of Economics, 116(2), 447-487.

Benabou, R., \& Tirole, J. (2006). Belief in a just world and redistributive politics. Quarterly Journal of Economics, 121(2), 699-746.

Boadway, R., \& Marchand, M. (1995). The use of public expenditures for redistributive purposes. Oxford Economic Papers, 47, 45-59. 
Chetty, R., Looney, A., \& Kroft, K. (2009). Salience and taxation: Theory and evidence. American Economic Review, 99(4), 1145-1177.

Clark, L.A., \& Watson, D. (1995). Constructing validity: Basic issues in objective scale development. Psychological Assessment, 7(3), 309-319.

Djanali, I., \& Sheehan-Connor, D. (2012). Tax affinity hypothesis: Do we really hate paying taxes? Journal of Economic Psychology, 33(4), 758-775.

Durham, Y., Manly, T. S., \& Ritsema, C. (2014). The effects of income source, context, and income level on tax compliance decisions in a dynamic experiment. Journal of Economic Psychology, 40, 220-233.

Eckel, C. C., Grossman, P. J., \& Johnston, R. M. (2005). An experimental test of the crowding out hypothesis. Journal of Public Economics, 89, 1543-1560.

Etheridge, E. (2009). 'Going Galt': Everyone's doing it! New York Times (March 6), http://opinionator.blogs.nytimes.com/2009/03/06/going-galt-everyones-doing-it.

Fochmann, M., Weimann, J., Blaufus, K., Hundsdoerfer, J., \& Kiesewetter, D. (2013). Net wage illusion in a real-effort experiment. Scandinavian Journal of Economics, 115(2), 476-484.

Frank, D. H., Wertenbroch, K., \& Maddux, W. W. (2015). Performance pay or redistribution? Cultural differences in just-world beliefs and preferences for wage inequality. Organizational Behavior and Human Decision Processes, 130, 160-170.

Gal, D., \& Liu, W. (2011). Grapes of wrath: The angry effects of self-control. Journal of Consumer Research, 38(3), 445-458.

Gangl, K., Muehlbacher, S., de Groot, M., Goslinga, S., Hofmann, E., Kogler, C., Antonides, G., \& Kirchler, E. (2013). "How can I help you?" Perceived service orientation of tax authorities and tax compliance. FinanzArchiv: Public Finance Analysis, 69, 487-510.

Graham, J., Haidt, J., \& Nosek, B. A. (2009). Liberals and conservatives rely on different sets of moral foundations. Journal of Personality and Social Psychology, 96(5), 1029-1046.

Hair, J. F., Anderson, R. E., Tatham, R. L., \& Black, B. (2006). Multivariate data analysis. Prentice Hall, Upper Saddle River, NJ.

Hardisty, D. J., Johnson, E. J., \& Weber, E. U. (2010). A dirty word or a dirty world? Attribute 
framing, political affiliation, and query theory. Psychological Science, 21(1), 86-92.

Helderman, R. S. (2012). Romney's equating of taxes and charitable giving sparks debate. Washington Post (August 18), http://wpo.st/VWBV0.

Hogg, M. A., \& Smith, J. R. (2007). Attitudes in social context: A social identity perspective. European Review of Social Psychology, 18, 89-131.

Kahan, D. M. (2012). Cultural cognition as a conception of the cultural theory of risk. In S. Roeser S (Ed.), Handbook of risk theory (725-759). Springer Netherlands.

Kahan, D. M., Braman, D., Gastil, J., Slovic, P., \& Mertz, C. K. (2007). Culture and identityprotective cognition: Explaining the white-male effect in risk perception. Journal of Empirical Legal Studies, 4(3), 465-505.

Kahan, D. M., Jenkins-Smith, H., \& Braman, D. (2011). Cultural cognition of scientific consensus. Journal of Risk Research, 14(2), 147-174.

Kahan, D. M., Peters, E., Wittlin, M., Slovic, P., Ouellette, L. L., Braman, D., \& Mandel, G. (2012). The polarizing impact of science literacy and numeracy on perceived climate change risks. Nature Climate Change, 2, 732-735.

Keane, M. P. (2011). Labor supply and taxes: A survey. Journal of Economic Literature, 49, 961-1075.

Kessler, J. B., \& Norton, M. I. (2016). Tax aversion in labor supply. Journal of Economic Behavior and Organization, 124, 15-28.

Kirchler, E., Hoelzl, E., \& Wahl, I. (2008). Enforced versus voluntary tax compliance: The "slippery slope" framework. Journal of Economic Psychology, 29, 210-225.

Kirchler, E., Kogler, C., \& Muehlbacher, S. (2014). Cooperative tax compliance: From deterrence to deference. Current Directions in Psychological Science, 23, 87-92.

Krugman, P. (2011). Taxing job creators. New York Times (November 22), http://krugman.blogs.nytimes.com/2011/11/22/taxing-job-creators.

Kuziemko, I., Norton, M. I., Saez, E., \& Stantcheva, S. (2015). How elastic are preferences for redistribution? Evidence from randomized survey experiments. American Economic Review, 105(4), 1478-1508.

This article is protected by copyright. All rights reserved. 
Lamberton, C. (2013). A spoonful of choice: How allocation increases satisfaction with tax payments. Journal of Public Policy Marketing, 32(2), 223-238.

LeBoeuf, R. A., Shafir, E., \& Bayuk, J. B. (2010). The conflicting choices of alternating selves. Organizational Behavior and Human Decision Processes, 111(1), 48-61.

Lepore, J. (2012). Tax time. New Yorker (November 26), http://www.newyorker.com/magazine/2012/11/26/tax-time.

Lerner, M. J. (1982). The belief in a just world. Plenum Press, New York.

Matthews, C. (2014). Republicans for wealth redistribution? Fortune (September 23), http://fortune.com/2014/09/23/republicans-wealth-redistribution.

McCaffery, E. J., \& Baron, J. (2006). Thinking about tax. Psychology, Public Policy, and Law, 12(1), 106-135.

Mulligan, C. B. (2010). The upside of an impenetrable tax code. New York Times (April 14), http://economix.blogs.nytimes.com/2010/04/14/the-upside-of-an-impenetrable-tax-code.

Norton, M. I., \& Ariely, D. (2011). Building a better America-One wealth quintile at a time. Perspectives on Psychological Science, 6(1), 9-12.

Oyserman, D. (2007). Social identity and self-regulation. In A. Kruglanski, \& T. Higgins (Eds.), Handbook of social psychology (432-453), Guilford, New York.

Oyserman, D. (2009). Identity-based motivation: Implications for action-readiness, proceduralreadiness, and consumer behavior. Journal of Consumer Psychology, 19(3), 250-260.

Pew Research. (2015). Federal tax system seen in need of overhaul. (March 19), http://www.people-press.org/2015/03/19/federal-tax-system-seen-in-need-of-overhaul.

Reed, A., Forehand, M. R., Puntoni, S., \& Warlop, L. (2012). Identity-based consumer behavior. International Journal of Research in Marketing, 29(4), 310-321.

Rees-Jones, A., \& Taubinsky, D. (2016). Heuristic perceptions of the income tax: Evidence and implications for debiasing. Working paper, University of Pennsylvania, Philadelphia.

Rosenman, M. (2012). Paying taxes and giving to charity aren't the same thing. Chronicle 
of Philanthropy (September 4), https://philanthropy.com/article/Paying-TaxesGivingto/156155.

Rubin, Z., \& Peplau, L. A. (1975). Who believes in a just world? Journal of Social Issues, 31(3), 65-89.

Rushton, J. P., Chrisjohn, R. D., \& Fekken, G. C. (1981). The altruistic personality and the selfreport altruism scale. Personality and Individual Differences, 2(4), 293-302.

Saez, E., Slemrod, J., \& Giertz, S. H. (2012). The elasticity of taxable income with respect to marginal tax rates: A critical review. Journal of Economic Literature, 50, 3-50.

Srna, S., Zauberman, G., \& Schrift, R. (2015). A prediction gap in the effect of income tax on effort. Working paper, University of Pennsylvania, Philadelphia.

Surowiecki, J. (2014). Moaning moguls. New Yorker (July 7), http://www.newyorker.com/magazine/2014/07/07/moaning-moguls

Sussman, A. B., \& Olivola, C. Y. (2011). Axe the tax: Taxes are disliked more than equivalent costs. Journal of Marketing Research, 48(SI), S91-S101.

Torgler, B. (2002). Speaking to theorists and searching for facts: Tax morale and tax compliance in experiments. Journal of Economic Surveys, 16, 657-683.

Tullock, G. (1971). The charity of the uncharitable. Economic Inquiry, 9, 379-392.

van Dijke, M., \& Verboon, P. (2010). Trust in authorities as a boundary condition to procedural fairness effects on tax compliance. Journal of Economic Psychology, 31, 80-91.

This article is protected by copyright. All rights reserved. 


\section{Appendix A}

Correlations between egalitarianism, communitarianism, and Graham, Haidt, and Nosek's (2009) "moral foundations"

\begin{tabular}{|l|cccccc|}
\hline & Communitarianism & Harm-Avoidance & Fairness & $\begin{array}{c}\text { Loyalty to } \\
\text { Ingroup }\end{array}$ & $\begin{array}{c}\text { Respect for } \\
\text { Authority }\end{array}$ & Purity \\
\hline Egalitarianism & $.29^{* *}$ & $.30^{* *}$ & $.36^{* *}$ & $-.29^{* *}$ & $-.39^{* *}$ & $-.36^{* *}$ \\
Communitarianism & & $.21^{* *}$ & $.22^{* *}$ & .11 & .02 & $.12^{* *}$ \\
Harm-Avoidance & & & $.48^{* *}$ & $.13^{*}$ & .04 & $.17^{* *}$ \\
Fairness & & & .05 & -.00 & .04 \\
Loyalty to Ingroup & & & & & $.66^{* *}$ & $.50^{* *}$ \\
Respect for Authority & & & & & $.56^{* *}$ \\
\hline
\end{tabular}

Note: $* * p<.01, * p<.05$. Survey conducted via Amazon Mechanical Turk $(\mathrm{N}=305)$.

This article is protected by copyright. All rights reserved. 


\section{Appendix B}

Experiments 1 and 2: Sample matrix of zeros and ones

How many zeros are in the table displayed below?

$\begin{array}{lllllllllllllll}0 & 1 & 0 & 1 & 0 & 1 & 0 & 1 & 1 & 0 & 0 & 1 & 0 & 0 & 0\end{array}$

$\begin{array}{lllllllllllllll}0 & 1 & 0 & 1 & 0 & 1 & 0 & 1 & 0 & 1 & 1 & 0 & 0 & 1 & 0\end{array}$

$\begin{array}{lllllllllllllll}1 & 0 & 1 & 1 & 1 & 0 & 0 & 0 & 1 & 1 & 0 & 0 & 0 & 1 & 0\end{array}$

$\begin{array}{llllllllllllllll}1 & 1 & 0 & 1 & 0 & 1 & 0 & 0 & 1 & 0 & 0 & 1 & 0 & 1 & 1\end{array}$

$\begin{array}{lllllllllllllll}0 & 0 & 1 & 1 & 0 & 1 & 0 & 1 & 0 & 0 & 1 & 0 & 1 & 1 & 0\end{array}$

$\begin{array}{llllllllllllllll}0 & 1 & 0 & 1 & 0 & 1 & 0 & 0 & 0 & 1 & 0 & 1 & 0 & 1 & 1\end{array}$

$\begin{array}{lllllllllllllll}1 & 1 & 1 & 0 & 1 & 1 & 1 & 1 & 1 & 1 & 1 & 0 & 1 & 0 & 0\end{array}$

$\begin{array}{lllllllllllllll}0 & 0 & 1 & 1 & 0 & 0 & 0 & 1 & 0 & 1 & 0 & 1 & 1 & 0 & 1\end{array}$

$\begin{array}{lllllllllllllll}0 & 1 & 1 & 1 & 1 & 0 & 0 & 1 & 0 & 1 & 0 & 1 & 0 & 0 & 0\end{array}$

$\begin{array}{lllllllllllllll}1 & 0 & 0 & 0 & 1 & 0 & 1 & 0 & 1 & 0 & 0 & 1 & 0 & 1 & 1\end{array}$

Experiment 1: Sample paychecks (for rounds in which the participant provided an acceptable response)

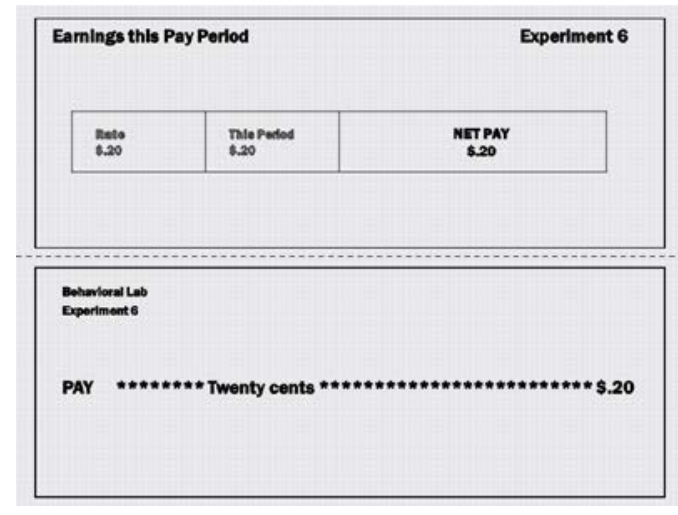

Control condition

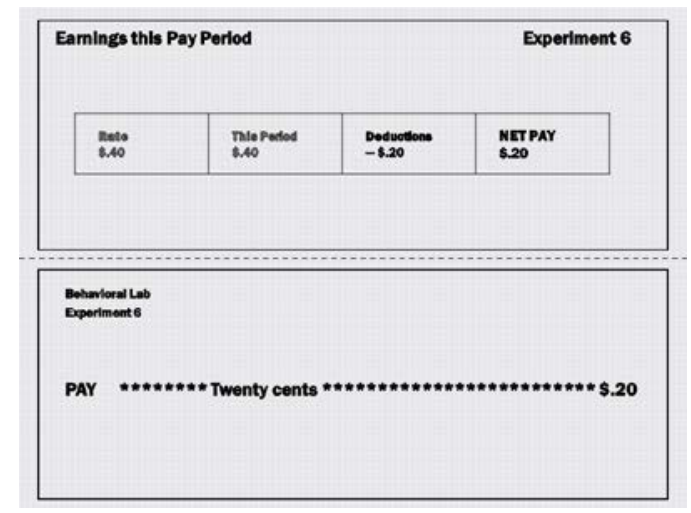

Tax condition

This article is protected by copyright. All rights reserved. 
Short-Form of Cultural Cognition Worldview scale (Kahan, Jenkins-Smith, \& Braman, 2011)

Responses to each item were made on a six-point scale, ranging from Strongly Disagree to Strongly Agree. Responses were coded such that higher scores were indicative of higher egalitarianism and higher communitarianism.

\section{Egalitarianism subscale}

1. We have gone too far in pushing equal rights in this country. (reverse-scored)

2. Our society would be better off if the distribution of wealth was more equal.

3 . We need to dramatically reduce inequalities between the rich and the poor, whites and people of color, and men and women.

4. Discrimination against minorities is still a very serious problem in our society.

5. It seems like blacks, women, homosexuals and other groups don't want equal rights, they want special rights just for them. (reverse-scored)

6. Society as a whole has become too soft and feminine. (reverse-scored)

Communitarianism subscale

1. The government interferes far too much in our everyday lives. (reverse-scored)

2. Sometimes government needs to make laws that keep people from hurting themselves.

3. It's not the government's business to try to protect people from themselves. (reverse-scored)

4. The government should stop telling people how to live their lives. (reverse-scored)

5. The government should do more to advance society's goals, even if that means limiting the freedom and choices of individuals.

6. Government should put limits on the choices individuals can make so they don't get in the way of what's good for society. 
Experiment 2: Payment animations (for rounds in which the participant provided an acceptable response). Dashed arrows represent the movement that was displayed to participants. Participants in this experiment were part of a course ("Mkt300"), participating as part of a course requirement, and tax revenues / matched revenues were allocated to students not currently enrolled in that course ("non-Mkt300 students").

\section{Control condition}
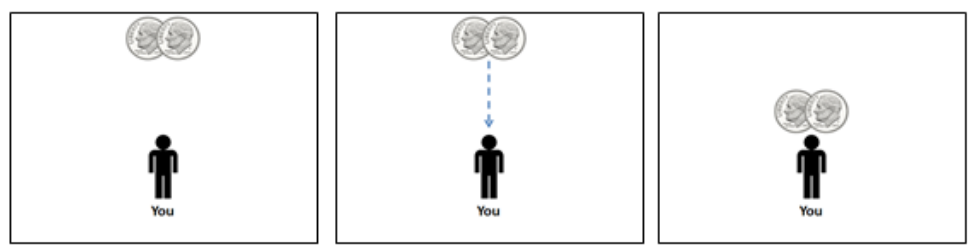

Tax condition
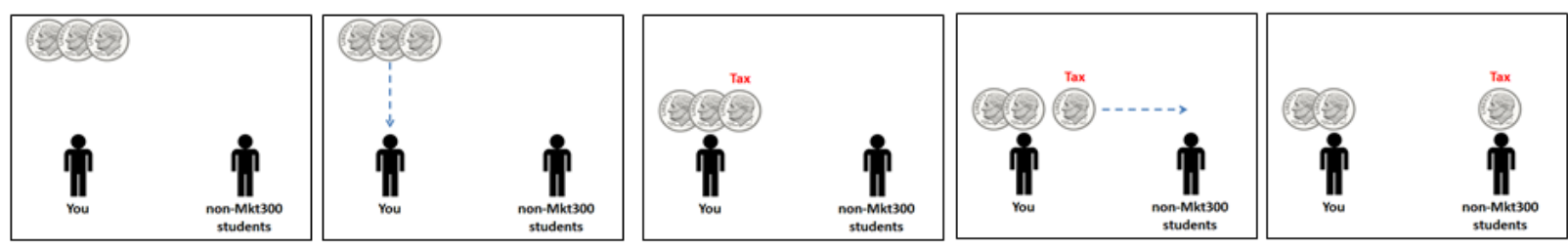

\section{Match condition}
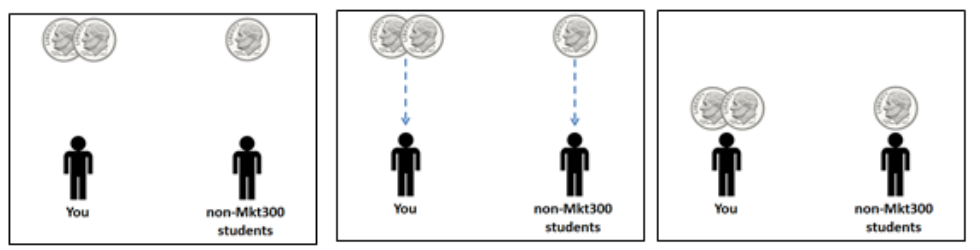

This article is protected by copyright. All rights reserved. 


\section{Appendix C}

Exploratory measures collected at the conclusion of Experiment 1, listed in order of administration

Four movie choices (e.g., Anger Management or Billy Madison), previously utilized as a measure of anger (Gal \& Liu, 2011)

How difficult did you find the earlier counting task? (1-7 scale)

What do you think the purpose of the counting study was? (open-ended)

\section{Exploratory measures collected at the conclusion of Experiment 2, listed in order of administration}

How difficult did you find the counting task? (1-7 scale)

Inclusion of other in the self scale (one item; Aron, Aron, \& Smollan, 1992), referring to you and other students

Self-report altruism scale (20 items; Rushton, Chrisjohn, \& Fekken, 1981)

How would you describe yourself politically? (Democrat / Republican / None of the above)

What do you think the purpose of the counting study was? (open-ended)

This article is protected by copyright. All rights reserved. 
Table 1: Unstandardized Coefficients from Regressions Predicting Total Earnings, Experiment 1

\begin{tabular}{|c|c|c|c|c|}
\hline & \multicolumn{2}{|c|}{ Model 1} & \multicolumn{2}{|c|}{ Model 2} \\
\hline & $\mathrm{B}$ & SE & $\mathrm{B}$ & SE \\
\hline Intercept & $85.69 * *$ & $(8.07)$ & $88.49 * *$ & $(8.29)$ \\
\hline Tax condition & -8.94 & $(11.40)$ & -17.98 & $(11.68)$ \\
\hline Egalitarianism & & & -3.70 & $(1.99)$ \\
\hline Communitarianism & & & 0.70 & $(1.58)$ \\
\hline Egalitarianism $\times$ Communitarianism & & & -0.33 & $(0.36)$ \\
\hline Tax $\times$ Egalitarianism & & & $9.09 * *$ & $(3.11)$ \\
\hline Tax $\times$ Communitarianism & & & 1.44 & $(2.36)$ \\
\hline Tax $\times$ Egalitarianism $\times$ Communitarianism & & & $1.52 * *$ & $(0.55)$ \\
\hline $\mathrm{N}$ & \multicolumn{2}{|c|}{233} & \multicolumn{2}{|c|}{233} \\
\hline $\mathrm{R}^{2}$ & \multicolumn{2}{|c|}{.003} & \multicolumn{2}{|c|}{.071} \\
\hline
\end{tabular}

Note: $* * p<.01$. Tax condition is a dummy variable $(1=$ Yes, $0=$ No). 
Table 2: Unstandardized Coefficients from Regressions Predicting Egalitarianism Scores, Communitarianism Scores, and Total Earnings, Experiment 1

\begin{tabular}{|c|c|c|c|c|c|c|c|c|c|c|}
\hline & \multirow{2}{*}{\multicolumn{2}{|c|}{$\begin{array}{c}\text { DV: } \\
\text { Egalitarianism } \\
\text { Score } \\
\text { Model 1 } \\
\end{array}$}} & \multirow{2}{*}{\multicolumn{2}{|c|}{$\begin{array}{c}\text { DV: } \\
\begin{array}{c}\text { Communitarianism } \\
\text { Score }\end{array} \\
\text { Model } 2 \\
\end{array}$}} & \multicolumn{6}{|c|}{$\begin{array}{c}\text { DV (Models 3-5): } \\
\text { Total Earnings }\end{array}$} \\
\hline & & & & & \multicolumn{2}{|c|}{ Model 3} & \multicolumn{2}{|c|}{ Model 4} & \multicolumn{2}{|c|}{ Model 5} \\
\hline & B & SE & B & $\mathrm{SE}$ & B & SE & B & $\mathrm{SE}$ & B & $\mathrm{SE}$ \\
\hline Intercept & $17.81 * *$ & $(0.44)$ & $22.44 * *$ & $(0.54)$ & $84.44 * *$ & (10.29) & $88.33 * *$ & (10.29) & $89.00 * *$ & $(13.81)$ \\
\hline Democrat & $3.44 * *$ & $(0.58)$ & $6.21 * *$ & $(0.70)$ & 3.28 & (16.70) & & & -1.27 & (19.09) \\
\hline Independent & $2.32 * *$ & $(0.63)$ & $3.35^{* *}$ & $(0.76)$ & & & -9.58 & (18.08) & -10.25 & $(20.72)$ \\
\hline Tax condition & & & & & -5.66 & (14.87) & -17.58 & (13.60) & -24.17 & $(21.31)$ \\
\hline Tax $\times$ Democrat & & & & & -7.95 & (23.32) & & & 10.56 & $(27.88)$ \\
\hline Tax $\times$ Independent & & & & & & & 28.56 & $(25.02)$ & 35.15 & $(29.98)$ \\
\hline $\mathrm{N}$ & \multicolumn{2}{|c|}{233} & \multicolumn{2}{|c|}{233} & \multicolumn{2}{|c|}{233} & \multicolumn{2}{|c|}{233} & \multicolumn{2}{|c|}{233} \\
\hline $\mathrm{R}^{2}$ & \multicolumn{2}{|c|}{.133} & \multicolumn{2}{|c|}{.253} & \multicolumn{2}{|c|}{.003} & \multicolumn{2}{|c|}{.009} & \multicolumn{2}{|c|}{.010} \\
\hline
\end{tabular}

Note: $* * p<.01$. Democrat, Independent, and Tax condition are dummy variables ( $1=\mathrm{Yes}, 0=\mathrm{No})$. 
Table 3: Unstandardized Coefficients from Regressions Predicting Total Earnings, Experiment 2

\begin{tabular}{|c|c|c|c|c|}
\hline & \multicolumn{2}{|c|}{ Model 1} & \multicolumn{2}{|c|}{ Model 2} \\
\hline & $\mathrm{B}$ & SE & $\mathrm{B}$ & SE \\
\hline Intercept & $61.35^{* *}$ & $(7.07)$ & $62.10 * *$ & $(7.19)$ \\
\hline Tax condition & -3.53 & $(10.00)$ & -5.74 & (10.08) \\
\hline Match condition & -10.68 & $(9.97)$ & -8.51 & $(10.35)$ \\
\hline Egalitarianism & & & -0.38 & $(1.29)$ \\
\hline Communitarianism & & & -3.00 & $(1.69)$ \\
\hline Egalitarianism $\times$ Communitarianism & & & -0.21 & $(0.21)$ \\
\hline Tax $\times$ Egalitarianism & & & 2.95 & $(1.90)$ \\
\hline Tax $\times$ Communitarianism & & & $6.05^{*}$ & $(2.55)$ \\
\hline Tax $\times$ Egalitarianism $\times$ Communitarianism & & & $0.79 *$ & $(0.38)$ \\
\hline Match $\times$ Egalitarianism & & & -1.02 & $(1.81)$ \\
\hline Match $\times$ Communitarianism & & & 2.83 & $(2.79)$ \\
\hline Match $\times$ Egalitarianism $\times$ Communitarianism & & & -0.14 & $(0.34)$ \\
\hline $\mathrm{N}$ & \multicolumn{2}{|c|}{358} & \multicolumn{2}{|c|}{358} \\
\hline $\mathrm{R}^{2}$ & \multicolumn{2}{|c|}{.003} & \multicolumn{2}{|c|}{.045} \\
\hline
\end{tabular}

Note: $* * p<.01, * p<.05$. Tax condition and Match condition are dummy variables $(1=$ Yes, $0=$ No). 
Figure 1: Heatmap displaying distribution of participants' egalitarian and communitarian attitudes in Experiment 1

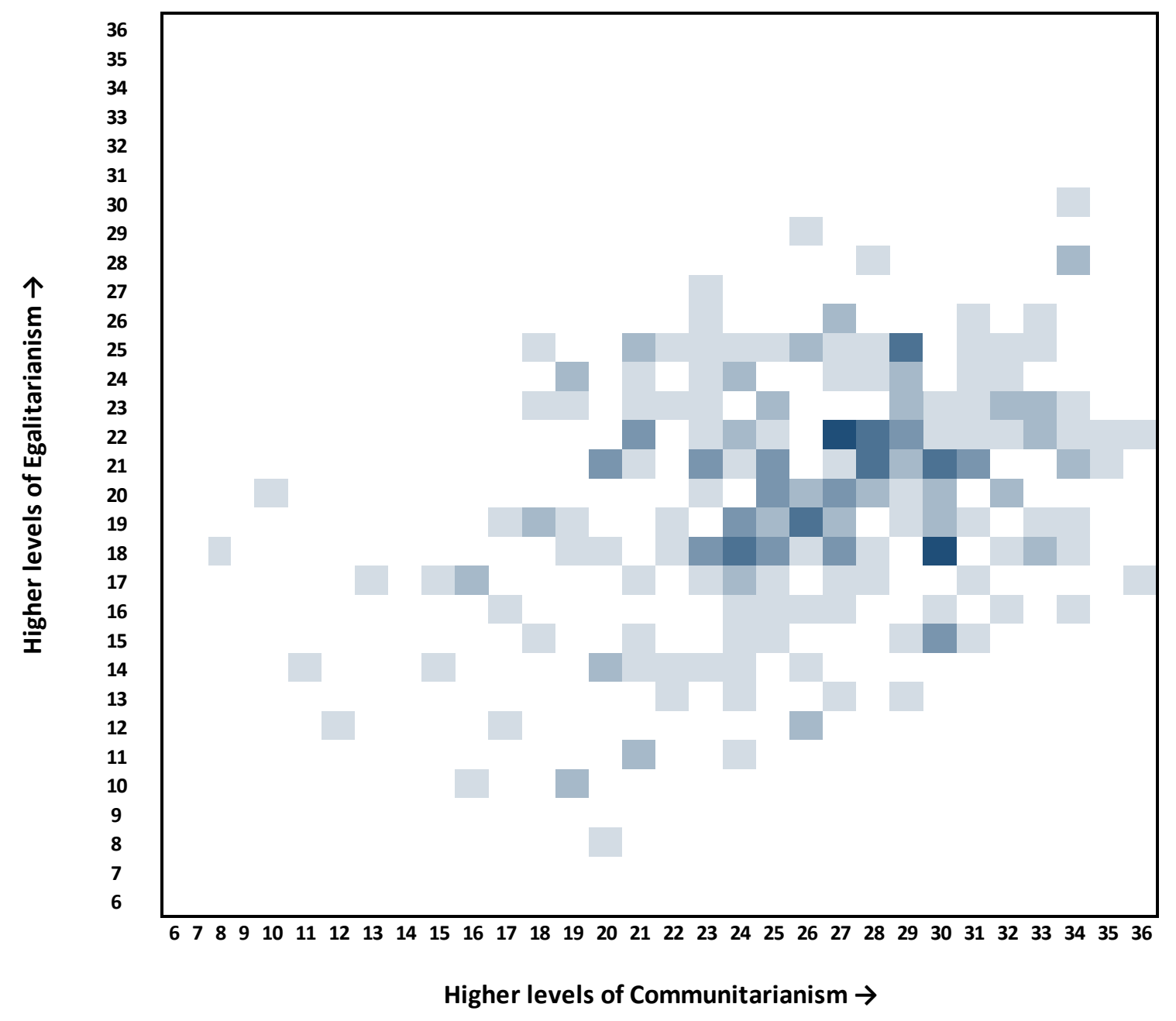

Note: The darker the pixel, the greater number of participants who held those particular levels of egalitarianism and communitarianism. No color indicates that no participant held those particular levels of egalitarianism and communitarianism.

This article is protected by copyright. All rights reserved. 
Figure 2: Spotlight analysis of total earnings (in cents), Experiment 1

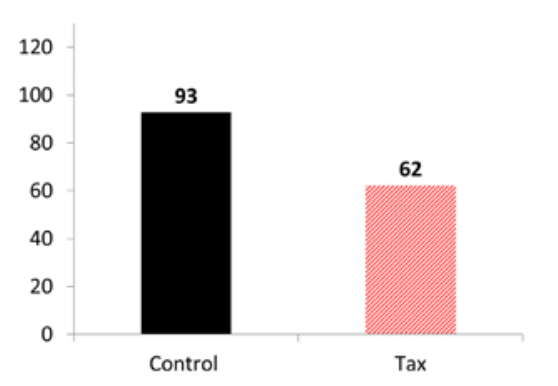

Low E / Low C

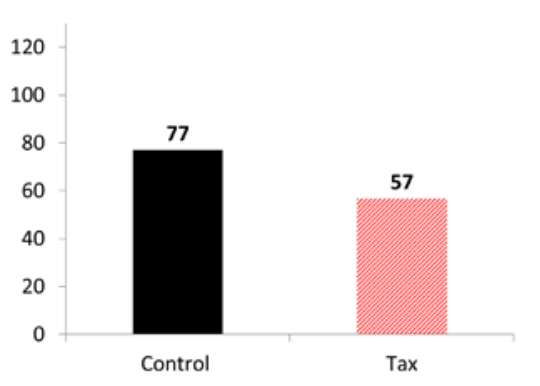

High E / Low C

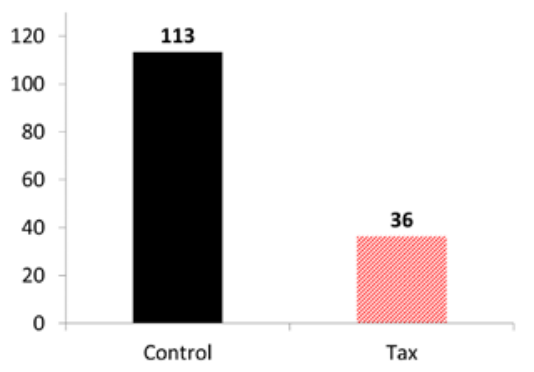

Low E / High C

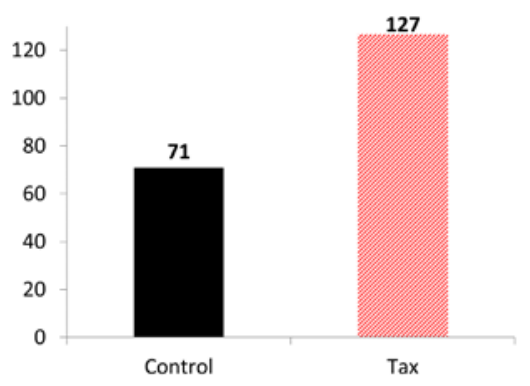

High E / High C

Note: These are predictions of the model at $1 S D$ above and below the mean levels of egalitarianism and communitarianism. 
Figure 3: Heatmap displaying distribution of participants' egalitarian and communitarian attitudes in Experiment 2

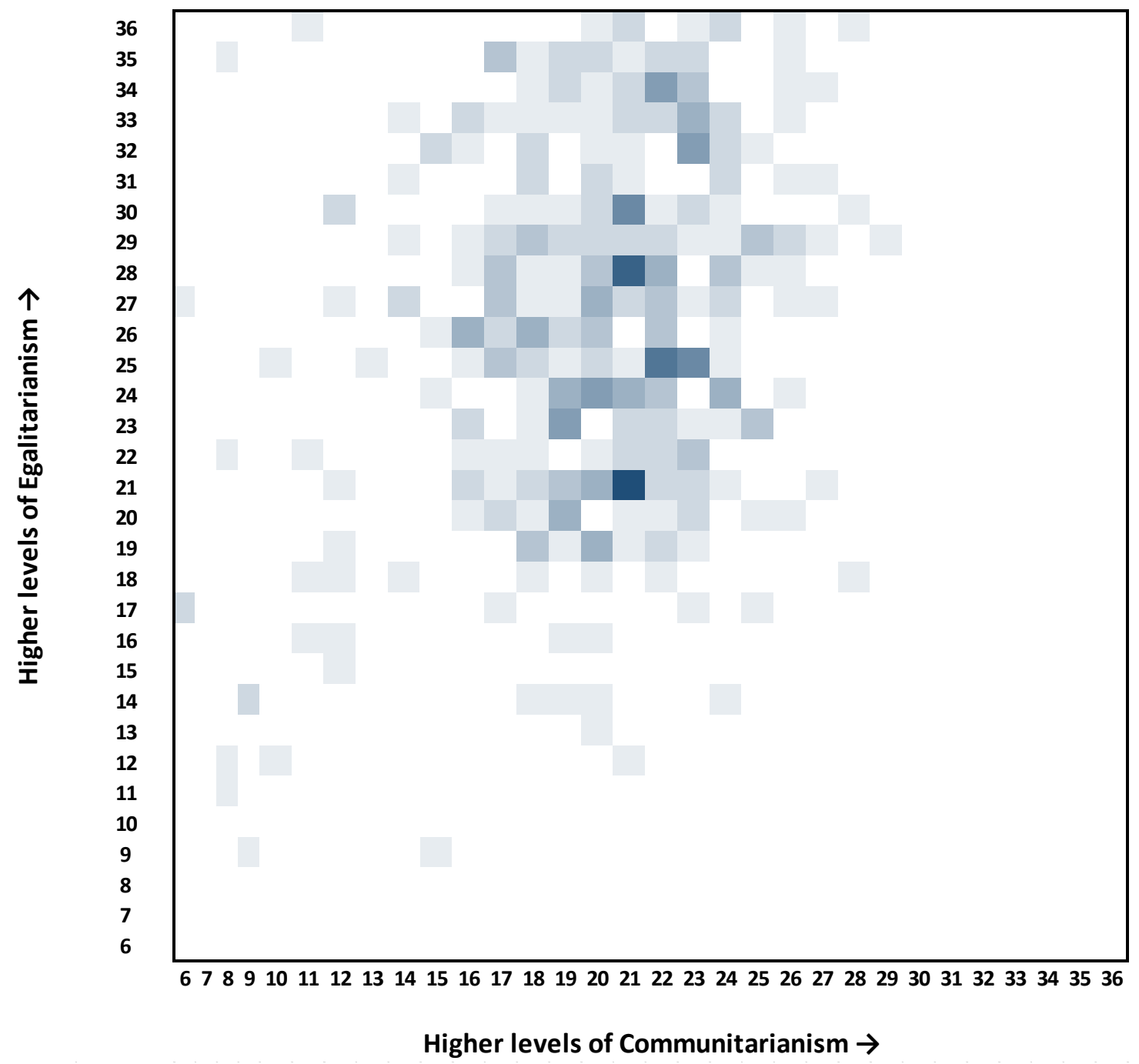

Note: The darker the pixel, the greater number of participants who held those particular levels of egalitarianism and communitarianism. No color indicates that no participant held those particular levels of egalitarianism and communitarianism.

This article is protected by copyright. All rights reserved. 
Figure 4: Spotlight analysis of total earnings (in cents), Experiment 2

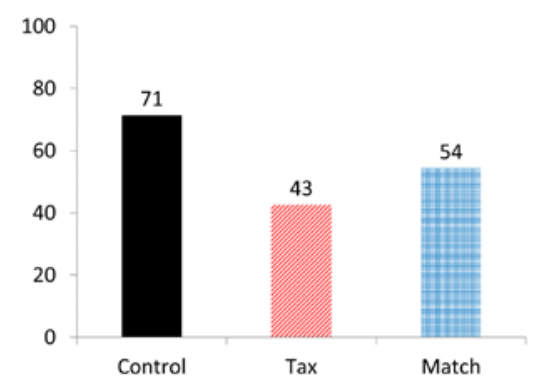

Low E / Low C

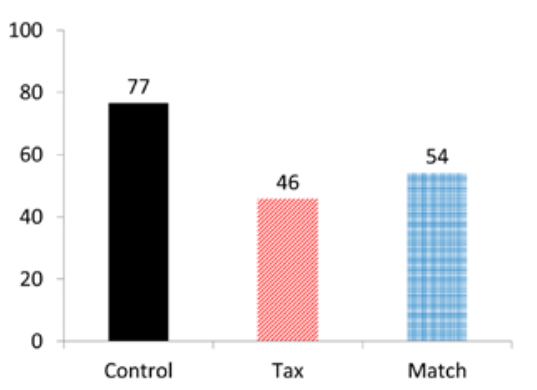

High E / Low C

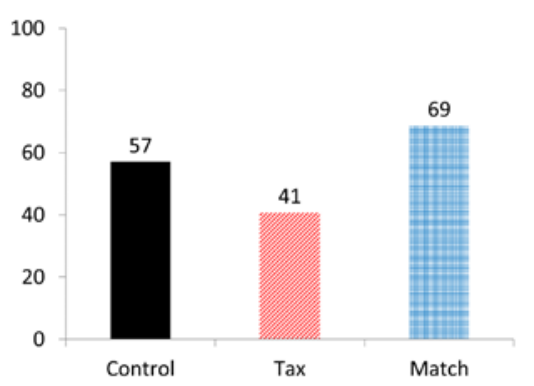

Low E / High C

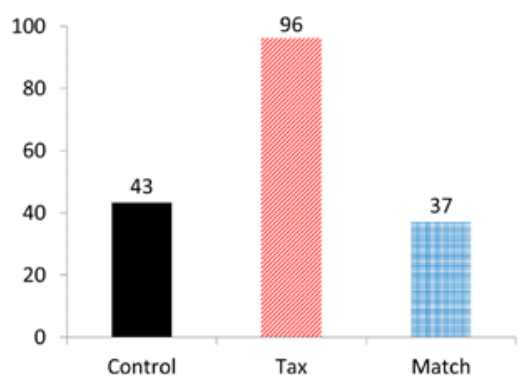

High E / High C

Note: These are predictions of the model at $1 S D$ above and below the mean levels of egalitarianism and communitarianism. 